\title{
Factores epidemiológicos Ro y Re durante la COVID-19: ¿qué son y en qué difieren?
}

Epidemiological factors Ro and Re during the COVID-19: what are they and how do they differ?

Fatores epidemiológicos Ro e Re durante a COVID-19: o que eles são e como diferem?

Como citar este articulo: Comincini Cantillo Eric, Wilches Visbal Jorge Homero, Saraví Fernando Daniel. Factores epidemiológicos R0 y Re durante la COVID-19: ¿qué son y en qué difieren?. Revista Cuidarte. 2021;12(1):e1393. http://dx.doi.org/10.15649/cuidarte.1393

Revista Cuidarte

dey Cuid. Ene. - Abril. 2021; 12(1): e1393

http://dx.doi.org/10.15649/cuidarte.1393

E-ISSN: 2346-3414

\footnotetext{
(1) Eric Comincini Cantillo

(1) Jorge Homero Wilches Visbal²

(1) Fernando Daniel Saraví
}

1 Unidad de Urgencias, Ejército Nacional de Colombia, Barranquilla, Colombia. Email: comincinieric56@gmail.com

2 Programas de Odontología y Medicina, Facultad de Ciencias de la Salud, Universidad del Magdalena, Santa Marta, Colombia. Email: jhwilchev@gmail.com

3 Instituto de Fisiología, Facultad de Ciencias Médicas, Universidad Nacional de Cuyo, Ciudad de Mendoza, Argentina. Email: fernando.saravi@hotmail.es

Estimada Editora,

Las enfermedades infecciosas son aquellas causadas por microbios patógenos tales como algunas bacterias, virus, parásitos, entre otros. Estas enfermedades pueden transmitirse, directa o indirectamente, de un individuo a otro'

La epidemiología estudia los procesos de salud y enfermedad que afectan a las poblaciones. Se interesa por conocer las características de los grupos que se ven afectados; cómo se distribuyen geográficamente y en el tiempo los eventos de salud y enfermedad; con qué frecuencia se manifiestan y cuáles son las causas o factores asociados a su surgimiento².

La COVID-19, una pandemia originada por un nuevo coronavirus conocido como SARS-CoV-2, se caracteriza por afectar al sistema respiratorio y por su alta tasa de transmisión. Dado que la COVID-19 es una enfermedad infecciosa, la epidemiologia juega un papel crucial en su análisis y control ${ }^{3}$.

El estudio de las epidemias se basa, en gran medida, en el uso de modelos epidemiológicos. Los modelos epidemiológicos se definen como una representación matemática o lógica de la

Dos de los factores de importancia epidemiológica tenidos en cuenta para la predicción del impacto del curso epidémico son el número básico de reproducción y el número efectivo de reproducción. transmisión de una patología o enfermedad y de los sucesos y cambios relacionados con ella ${ }^{4}$. Dos de los factores de importan-

Recibido: julio 22 de 2020

Aceptado: septiembre 10 de 2020

Publicado: noviembre 13 de 2020 $\nabla *$ Correspondencia

Eric Comincini Cantillo

E-mail:comincinieric56@gmail.com 
cia epidemiológica tenidos en cuenta para la predicción del impacto del curso epidémico son el número básico de reproducción y el número efectivo de reproducción. Ambos factores ofrecen una visión general acerca de la eficacia de las medidas de contención contra la epidemia, así como un panorama en tiempo real de las posibles consecuencias sobre el sistema de salud y la población.

Debido a que en parte de la comunidad científica, el número básico y el número efectivo de reproducción se siguen utilizando de manera intercambiable ${ }^{5}$, vale la pena remarcar sus diferencias y establecer el contexto de aplicación para cada uno.

El numero básico de reproducción, $\mathrm{R}_{0}$, se define como el número promedio de individuos que pueden llegar a infectarse (casos secundarios) a partir del primer individuo infectado (caso primario) en una población completamente susceptible $e^{6-8}$. El $\mathrm{R}_{0}$ se estima a partir de datos obtenidos en campo ingresados en modelos matemáticos ${ }^{5}$. Para modelos epidemiológicos simples, como el Susceptibles-Infectados-Recuperados (SIR), el $\mathrm{R}_{0}$ viene dado por el cociente entre la tasa de contagio, $\beta$, y la tasa de recuperación, $\gamma$, es decir ${ }^{7}$,

$$
R_{0}=\frac{\beta}{\gamma}
$$

Siendo así, el $\mathrm{R}_{0}$, puede interpretarse como la velocidad inicial de propagación de la infección (contagiosidad) en una población sin inmunización alguna ${ }^{5}$. Por ejemplo, si un brote tuviese un $\mathrm{R}_{0}=5$, esto significaría que el primer individuo que desarrolló la infección la transmitió a cinco individuos más. El $\mathrm{R}_{0}$ depende de factores biológicos, socio-conductuales y ambientales al inicio del brote. En otras palabras, el $\mathrm{R}_{0}$ es función de la contagiosidad y patogenicidad del microorganismo, de la proporción de individuos susceptibles dentro de la población y de la cantidad de contactos del primer infectado ${ }^{5,6}$.

La potencia de progresión de una enfermedad contagiosa viene dada por el valor del $\mathrm{R}_{0}{ }^{6}$. $\mathrm{Si}$ el valor de $R_{0}$ es mayor que $1\left(R_{0}>1\right)$, esto es, la tasa de contagio es mayor que la tasa de recuperación, se espera que se inicie un brote y que progrese a epidemia. Por el contrario, cuando el valor de $\mathrm{R}_{0}$ es menor que $1\left(\mathrm{R}_{0}<1\right)$, la tasa de recuperación supera a la tasa de contagio, indicando que el brote iniciado está bajo control, no se convertirá en epidemia y finalizará rápidamente ${ }^{7,9}$.

En brotes generados por un agente infeccioso desconocido (por ejemplo: un virus o bacteria), entre más temprano y con mayor calidad se obtengan los datos, más próximo estará el valor estimado del $\mathrm{R}_{0}$ de su valor real. Como la realización de las mediciones no suele coincidir con el momento del primer contagio $(t=0)$, lo que en verdad se suele medir es la transmisibilidad del virus cuando cierta parte de la población no es inmune, es decir, el número efectivo de reproducción ${ }^{5}$. En consecuencia, el número efectivo de reproducción es un factor más realista que el $\mathrm{R}_{0}$ ya que este último se basa en un escenario ideal de recopilación de información.

El número efectivo de reproducción, $\mathrm{R}_{\mathrm{e}}$, viene definido como el número promedio de individuos que pueden llegar a ser infectados por un individuo cualquiera en un determinado instante de tiempo después de iniciado el brote $(t>0)$, o sea ${ }^{7}$, 


$$
R_{e}(t)=R_{0} \times\left(\frac{S}{N}\right)
$$

donde $\mathrm{S}$ es la cantidad de individuos susceptibles al contagio y $\mathrm{N}$ es el universo poblacional ${ }^{5,10}$.

Así, la fracción de susceptibles $\left(\frac{\$}{N}\right.$ va disminuyendo a medida que la población se inmuniza natural (individuos recuperados) o ar tificialmente (individuos vacunados), así como a medida que los individuos fallecen.

A diferencia del $\mathrm{R}_{0}$, el $\mathrm{R}_{\mathrm{e}}$ varía temporalmente con la tasa de contacto efectiva, el comportamiento y la organización social y la fracción de recuperados y fallecidos durante el curso epidémico. Dado que el $\mathrm{R}_{\mathrm{e}}$ es críticamente influenciado por el número de susceptibles, el comportamiento de los individuos (por ejemplo, distanciamiento social) es determinante para contener una epidemia ${ }^{5}$. En el caso en que el $\mathrm{R}_{\mathrm{e}}<1$ el evento epidémico tenderá a desaparecer rápidamente, mientras que si $R_{e}>1$ se espera que la epidemia continúe. Luego, entre más alto el valor del $\mathrm{R}_{\mathrm{e}}$ más difícil será controlar una epidemia y evitar su progresión a pandemia ${ }^{5}$.

La relevancia práctica de estos dos factores radica en que ofrecen un panorama del impacto sanitario de una enfermedad infecciosa, es decir, cuán congestionado puede llegar a estar el sistema de atención en salud como consecuencia de la propagación de la infección. En Colombia, por ejemplo, el $\mathrm{R}_{0}$ de la COVID-19, se estimó en 1,5 para el mes de marzo (poco tiempo después del inicio del brote $)^{9}$. Entretanto, las estimaciones del $R_{e}$ fueron de 1,67 en abril, 1,52 en mayo y 1,17 en julio ${ }^{11}$, lo cual da cuenta de la variabilidad temporal del valor de $R_{e}$ en relación con las medidas de contención empleadas. Además, a partir de los valores del $\mathrm{R}_{\mathrm{e}}$ para esos tres meses, se proyecta que la pandemia estaría cediendo para los meses de agosto o septiembre toda vez que el $\mathrm{R}_{\mathrm{e}}$ está aproximándose a 1,00.

En conclusión, cuando alguien se refiera al $\mathrm{R}_{0}$, lo más probable es que sea al $\mathrm{R}_{\mathrm{e}}$; el $\mathrm{R}_{0}$ indica si va a ocurrir o no una epidemia mientras que el $\mathrm{R}_{\mathrm{e}}$ se refiere a si la epidemia (ya existente) está siendo controlada o no; el $\mathrm{R}_{0}$ es un valor estático en el tiempo, el $\mathrm{R}_{\mathrm{e}}$ no; las medidas de contención se diseñan para disminuir el $R_{e}$ no el $R_{0} y$, finalmente, una vacuna tendría por objeto anular la fracción de susceptibles afectando al $\mathrm{R}_{\mathrm{e}}$ no al $\mathrm{R}_{0}$.

Conflicto de intereses: ninguno declarado.

\section{Referencias}

1. Organización Mundial de la Salud. Infectious Diseases [Internet]. 2020 [citado 18 de julio de 2020]. Disponible en: https://www.who.int/topics/infectious_diseases/es/\#: :text

2. Organización Mundial de la Salud. Epidemiología [Internet]. 2020 [citado 18 de julio de 2020]. Disponible en: https://www.who.int/topics/epidemiology/es/

3. Organización Mundial de la Salud. Novel Coronavirus - China [Internet]. 2020 [citado 19 de julio de 2020]. Disponible en: https://www.who.int/csr/don/12-january-2020-novel-coronavirus-china/en/

4. Dubé C, Garner G, Stevenson M, Sanson R, Estrada C, Willeberg P. Utilización de modelos epidemiológicos para la gestión de las enfermedades animales. En: Conf OIE. 2007. p. 25-35. Disponible en: https://www.oie.int/doc/ged/D4533.PDF . 
5. Aronson JK, Brassey J, Mahtani KR. "When will it be over?": An introduction to viral reproduction numbers, R0 and Re [Internet]. Centre for Evidence-Based Medicine, Nuffield Department of Primary Care Health Sciences, University of Oxford. 2020. p. 1-9. Disponible en:

https://www.cebm.net/wp-content/uploads/2020/04/"When-will-it-be-over_"_-An-introduction-to-viral-reproduction-numbers-1.pdf

6. Delamater PL, Street EJ, Leslie TF, Yang YT, Jacobsen KH. Complexity of the basic reproduction number (R0). Emerg Infect Dis [Internet]. 2019;25(1):1-4. Disponible en: https://doi.org/10.3201/eid2501.171901

7. Ridenhour B, Kowalik JM, Shay DK. El número reproductivo básico (R0): Consideraciones para su aplicación en la salud pública. Am J Public Health. 2018;108(1):S455-65. https://doi.org/10.2105/AJPH.2013.301704s

8. Van den Driessche P. Reproduction numbers of infectious disease models. Infect Dis Model. 2017;2(3):288-303. https://doi.org/10.1016/j.idm.2017.06.002

9. Manrique Abril FG, Agudelo Calderón CA, González Chordá VM, Gutiérrez Lesmes O, Téllez Piñerez CF, Herrera Amaya G. Modelo SIR de la pandemia de COVID-19 en Colombia. Rev Salud Pública 2020;22(1):1-9. https://doi.org/10.15446/rsap.v22n2.85977

10.Nishiura H, Chowell G. The effective reproduction number as a prelude to statistical estimation of time-dependent epidemic trends. En: Mathematical and Statistical Estimation Approaches in Epidemiology. 2009. p. 103-21. https://doi.org/10.1007/978-90-481-2313-1_5

11.Instituto Nacional de Salud. Número reproductivo efectivo nacional [Internet]. 2020 [citado 20 de julio de 2020]. Disponible en:

https://www.ins.gov.co/Direcciones/ONS/modelos-de-estimacion 